\title{
Uneven use of noninvasive ventilation in acute respiratory failure in Europe
}

\section{To the Editors:}

We read with great interest the paper by CRIMI et al. [1], recently published in the European Respiratory Journal, on routine use of noninvasive ventilation (NIV) in Europe. Application of NIV during acute respiratory failure in exacerbated chronic obstructive pulmonary disease patients is recognised as one of the few procedures that can reduce mortality [2]. We congratulate CRIMI et al. [1] on the important idea of exploring current use and methodology of treatment of acute respiratory failure with NIV throughout Europe. Until now, most of the data about NIV in the medical literature have originated from clinical trials performed in well-equipped and experienced medical centres, and little was known about its use in general clinical practice.

However, it would be difficult to agree with the authors' statement in the Discussion section: "In this large European, web-based survey we have demonstrated that the use of NIV, as perceived by the physicians, is relatively homogeneously spread throughout the different geographical regions and considerably high" [1].

CRIMI et al. [1] arbitrarily divided Europe geographically into Northern, Central and Southern regions, obtaining a comparable number of users across all regions. However, if we divide Europe along the 14th parallel passing between Berlin and Oder River, we would see a completely different picture. Putting aside five Middle-Eastern countries participating in the survey, we would see that 254 (98\%) of responders work in old (Western) European Community countries versus six (2\%) responders from Central and Eastern Europe.

In the Eurovent study, LLOYD-OWEN et al. [3] reported the considerable difference between Western and Central/Eastern Europe in the use of home mechanical ventilation (HMV) in chronic respiratory failure. In that study, Central Europe and Eastern Europe were represented by only one country, Poland, which reported a very low prevalence of this modality of treatment: 0.1 per 100,000 population. A national survey on the prevalence of HMV in Poland was recently performed; published 5 yrs after the Eurovent study, the survey reported that the prevalence of HMV in Poland had increased to 2.2 per 100,000 population [4], still a very low compared with Western Europe.

In 2010, we conducted a survey on the use of NIV in acute respiratory failure in all hospitals with a respiratory department/ward in Poland $(n=113)$ [5]. With a response rate of $41 \%$, we found that only 16 departments/wards (35\% of responders) had been providing NIV to patients with respiratory failure. Prevalence of NIV availability depended on the level of the hospital and the presence of a high-dependency unit within the department/ward.

Low availability of NIV in Poland is partly related to low gross national product per capita, resulting in an insufficient budget for health services. However, lack of experience in the organisation of high-dependency units within respiratory medicine departments and minimal opportunities for "handson" training in the application of NIV, certainly play important roles in hampering the rapid development of this method.

Although we could not find any data about the use of NIV in other Central and Eastern European countries, we suspect that the prevalence of NIV use is similar to that in Poland. This hypothesis may be indirectly supported by a low rate of abstracts presented during the European Respiratory Society (ERS) Congresses by authors from Central and Eastern Europe. During the ERS Congress in 2009 (Vienna, Austria), of the 76 abstracts presented during sessions led by the Noninvasive Ventilatory Support Group, only four originated from Central and Eastern European countries, compared with 56 from Western European countries. It is also worth noting that only $10 \%$ the members of the ERS Noninvasive Ventilatory Support Group represent Central and Eastern European countries.

In our opinion, the use of NIV in Europe is extremely heterogeneous, with a large gap between Western and Central/ Eastern Europe. The study by CRIMI et al. [1] represents the extent of NIV use among European leaders in NIV treatment, rather than in Europe as a whole.

\section{J. Nasiłowski, J. Zieliński and R. Chazan \\ Dept of Internal Medicine, Pneumonology and Allergology, Medi- cal University of Warsaw, Warsaw, Poland.}

Correspondence: J. Nasiłowski, Dept of Internal Medicine, Pneumonology and Allergology, Medical University of Warsaw, ul. Banacha 1a, 02-097, Warsaw, Poland. E-mail: jnasilowski@ wum.edu.pl

Statement of Interest: None declared.

\section{REFERENCES}

1 Crimi C, Noto A, Princi P, et al. A European survey of noninvasive ventilation practices. Eur Respir J 2010; 36: 362-369.

2 Lightowler JV, Wedzicha JA, Elliott MW, et al. Non-invasive positive pressure ventilation to treat respiratory failure resulting from exacerbations of chronic obstructive pulmonary disease: Cochrane systematic review and meta-analysis. BMJ 2003; 326: 185-187.

3 Lloyd-Owen SJ, Donaldson GC, Ambrosino N, et al. Patterns of home mechanical ventilation use in Europe: results of the Eurovent survey. Eur Respir J 2005; 25: 1025-1031.

4 Nasiłowski J, Szkulmowski Z, Migdał M, et al. [Prevalence of home mechanical ventilation in Poland]. Pneumonol Alergol Pol 2010; 78: 392-398.

5 Nasiłowski J, Leszczyk M, Bura M, et al. [A survey of noninvasive ventilation use in respiratory departments in Poland]. Pneumonol Alergol Pol 2010; 78: Suppl. 1, 43. 